\title{
Human 8-oxoguanine DNA glycosylase increases resistance to hyperoxic cytotoxicity in lung epithelial cells and involvement with altered MAPK activity
}

\author{
S Kannan ${ }^{1}$, H Pang ${ }^{2,3}$, DC Foster ${ }^{1}, \mathrm{Z} \mathrm{Ra0^{2,3 }}$ and $\mathrm{M} \mathrm{Wu}^{\star, 1}$ \\ ${ }^{1}$ Department of Biochemistry and Molecular Biology, University of North \\ Dakota School of Medicine and Health Sciences, Grand Forks ND58203, \\ China \\ 2 Laboratory of Structural Biology, Tsinghua University, Beijing 100084, China \\ ${ }^{3}$ National Laboratory of Bio-Macromolecules, Institute of Biophysics, Beijing \\ 100101, China \\ * Corresponding author: M Wu, Department of Biochemistry and Molecular \\ Biology, University of North Dakota School of Medicine and Health Sciences, \\ 501 N Columbia Road, Room 2726, UND, PO Box 9037, Grand Forks, \\ ND58203, China. Tel: + 86-701-777-4875; Fax: + 86-701-777-2382; \\ E-mail: minwu@medicine.nodak.edu
}

Received 12.4.05; revised 23.5.05; accepted 15.6.05; published online 29.7.05 Edited by $S$ Kornbluth

\begin{abstract}
It is unknown whether base excision DNA repair (BER) proteins interact with mitogen-activated protein kinases (MAPK) under oxidation. Here, we explored roles of BER proteins in signaling transduction involving MAPK during hyperoxia. We demonstrated that ERK1/2 phosphorylation in A549 cells was increased in $95 \% \mathrm{O}_{2}$. p38 activity in A549 cells was also increased by exposure to $95 \% \mathrm{O}_{2}$. To evaluate regulatory roles of MAPK, we have transduced $A 549$ cells and primary alveolar epithelial type II cells (AECII) to overexpress 8-oxoguanine DNA glycosylase (hOgg1). Overexpression of hOgg1 reduced hyperoxic toxicity in A549 and AECII cells. Furthermore, protection by BER against hyperoxia appeared to involve an upregulation of ERK1/2 and downregulation of p38. These observations demonstrate, for the first time, that reduction of hyperoxic toxicity by BER proteins may be involved with MAPK activity, thereby impacting cell survival. Furthermore, our studies suggest that modulation of MAPK may be used in combination with BER proteins to counteract hyperoxic toxicity.

Cell Death and Differentiation (2006) 13, 311-323.

doi:10.1038/sj.cdd.4401736; published online 29 July 2005
\end{abstract}

Keywords: MAPK; base excision repair; hyperoxia; DNA damage; lung epithelial cells; cell signaling

Abbreviations: ARDS, acute respiratory distress syndrome; ROS, reactive oxygen species; 8-oxo-dG, 7,8-dihydro-8-oxoguanine; BER, base excision DNA repair; MAPK, mitogen-activated protein kinases; hOgg1, human 8-oxoguanine DNA glycosylase; Fpg, formamidopyrimidine-DNA glycosylase; CFU, colony forming units; oxo-dG, 7,8-dihydro-8-oxoguanine; ECD, electron chemical detector

\section{Introduction}

Hyperoxia is often required to treat acute respiratory distress syndrome (ARDS), a common complication of severe diseases of various systems. However, hyperoxia can also cause severe lung toxicity. This toxicity may be induced by reactive oxygen species (ROS), although the molecular mechanism is not fully understood. ${ }^{1}$ Metabolite levels of ROS are easily cleared by antioxidants including superoxide dismutase, catalase, and glutathione peroxidases or lowmolecular-weight vitamins, ${ }^{2}$ but high levels of ROS can damage cellular machinery via several mechanisms including lipid peroxidation, ${ }^{3}$ enzyme consumption and ultimately DNA damage. Direct cytotoxicity is a major threat to both lung epithelial and endothelial cells, while DNA lesions can also have detrimental consequences due to genotoxicity or mutagenicity. ${ }^{4}$ Although chromosomal damage was indicated in hyperoxia samples a few decades ago, ${ }^{1}$ our lab is the first to directly demonstrate that hyperoxia causes lung cell DNAstrand breaks. ${ }^{5}$ Alveolar epithelial type I cells are thought to be the primary target of hyperoxic damage ${ }^{6-8}$ however, latest evidence also reveals that hyperoxia induces DNA damage in alveolar epithelial type II cells (AECII). ${ }^{9}$ Thus, DNA repair of epithelial cells is critical to the integrity of lung structure and function.

Hyperoxia, like other oxidations, results mainly in damage to bases and to the phosphodiester backbone of DNA, producing the most common adduct, 7,8-dihydro-8-oxoguanine (8-oxo-dG). The large parts of these nonbulky adducts are repaired by the base excision repair (BER) mechanism, ${ }^{5,10}$ with possible participation from nuclear excision repair. ${ }^{11}$ DNA glycosylases, of which there are several types, recognize damaged DNA bases and catalyze hydrolytic cleavage of the $N$-glycosyl bond linking the base to the sugar. A DNA polymerase then fills the resulting gap. Several glycosylases have been identified with the ability to remove oxidative base damage, including thymine glycol DNA glycosylase, hydroxymethyl uracil glycosylase, and 8-oxodG DNA glycosylase. ${ }^{12}$ The latter function is exerted by the human 8-oxoguanine DNA glycosylase (hOgg1), whose specificity for 8-oxo-dG is when formed in situ in DNA and hence paired opposite C. In Escherichia coli, formamidopyrimidine-DNA glycosylase (Fpg), a functional homologue of Ogg1 removes the 8-oxo-dG. ${ }^{13} \mathrm{~A}$ second 8-oxodG glycosylase, namely hOgg2, has a specificity for 8-oxo-dG when derived from the nucleotide pool and misincorporated opposite $\mathrm{G}$ or $\mathrm{A} .{ }^{14}$

Hyperoxic toxicity involves multiple signaling activities, but the molecular and cellular mechanisms are not completely understood. Several studies in adult mice and cultured cell lines have now shown that hyperoxia increases expression of the tumor suppressor protein p53 and its phosphorylation on serine $15^{15-18}$ It has been shown that p21 deficient cells 
succumb to severe toxicity under hyperoxic conditions. ${ }^{19}$ It is revealed that chemical toxicity may regulate $\mathrm{p} 53^{20}$ or $\mathrm{p} 21,{ }^{21}$ which are associated with altered expression of hOgg1. However, it is unclear whether hyperoxia can regulate or influence BER. A potential signaling pathway that may help connect activation of BER to G2 arrest involves the mitogenactivated protein kinases (MAPK).

MAPK are involved in numerous cell regulatory events including stress, transformation, and growth. ${ }^{22,23}$ MEK and MKK are the upstream kinases for ERK1/2 and p38 MAPK, respectively. Recently, the MAP kinase pathways have been linked to hyperoxic toxicity in both cell cultures and animal models; ${ }^{24,25}$ hyperoxia primarily activates ERK $1 / 2$ but less so p38. ${ }^{25}$ Buckley et al. have demonstrated that increased ERK1/2 may correlate with protection against hyperoxic toxicity in rats. ${ }^{24,26,27}$ p38 MAPK is linked to mismatch repair DNA response via the G2 checkpoint and to resistance to chemotherapeutic DNA-methylating agents. ${ }^{28}$ The only study relating $B E R$ to cell cycle regulators demonstrates the link of long-patch BER to p21 in mouse embryonic fibroblast cell line ${ }^{29}$ It is unclear whether BER pathway is linked to MAPK under hyperoxia. We explored the possibility that MAPK are involved in BER pathway in response to hyperoxic toxicity. Despite carcinoma originality, A549 cells have been widely used as type II-like cells for mechanistic studies of alveolar epithelial physiological properties and signaling pathways. $^{30,31}$ By transducing stable expression of hOgg1 in alveolar epithelial A549 cells with a retroviral vector as described previously, ${ }^{32}$ we report here that overexpression of BER DNA repair proteins can afford protection against hyperoxic toxicity. Further, the protective role of BER against hyperoxia appeared to involve an upregulation of ERK $1 / 2$ and downregulation of $\mathrm{p} 38$. Primary rat type II cells are also used to confirm the role of BER in hyperoxia.

\section{Results}

\section{Hyperoxia-induced DNA damage can be reduced by hOgg1 transduction}

Chromatin damage by hyperoxia was reported decades ago; ${ }^{1}$ however, particular DNA damage patterns have not been demonstrated until very recently. ${ }^{5}$ We examined the morphologic damage in cultured human alveolar epithelial A549 cells by hyperoxia using microscopy, and demonstrated less cell survival and altered shapes while the control cells appeared healthy (Figure 1a). A549 cells have been widely used as type II-like cells for mechanistic studies of alveolar epithelial physiological properties and signaling pathways. ${ }^{30,31}$ DNA single-strand breaks by hyperoxia were identified using the comet assay of A549 cells based on alkaline electrophoresis (Figure 1b). This result indicates that hyperoxic treatment increased DNA damage compared to the control. After exposure to hyperoxia for 2 days, the average of tail lengths for 75 control cells was $1.2 \pm 0.21$ arbitrary units $(\mu \mathrm{m})$, while $14.8 \pm 1.7 \mu \mathrm{m}$ in oxygen-treated cells $(P<0.01)$. To further identify the particular DNA adduct, we detected 8-oxo-dG and found a three-fold increase in 8-oxo-dG by 2-day hyperoxic
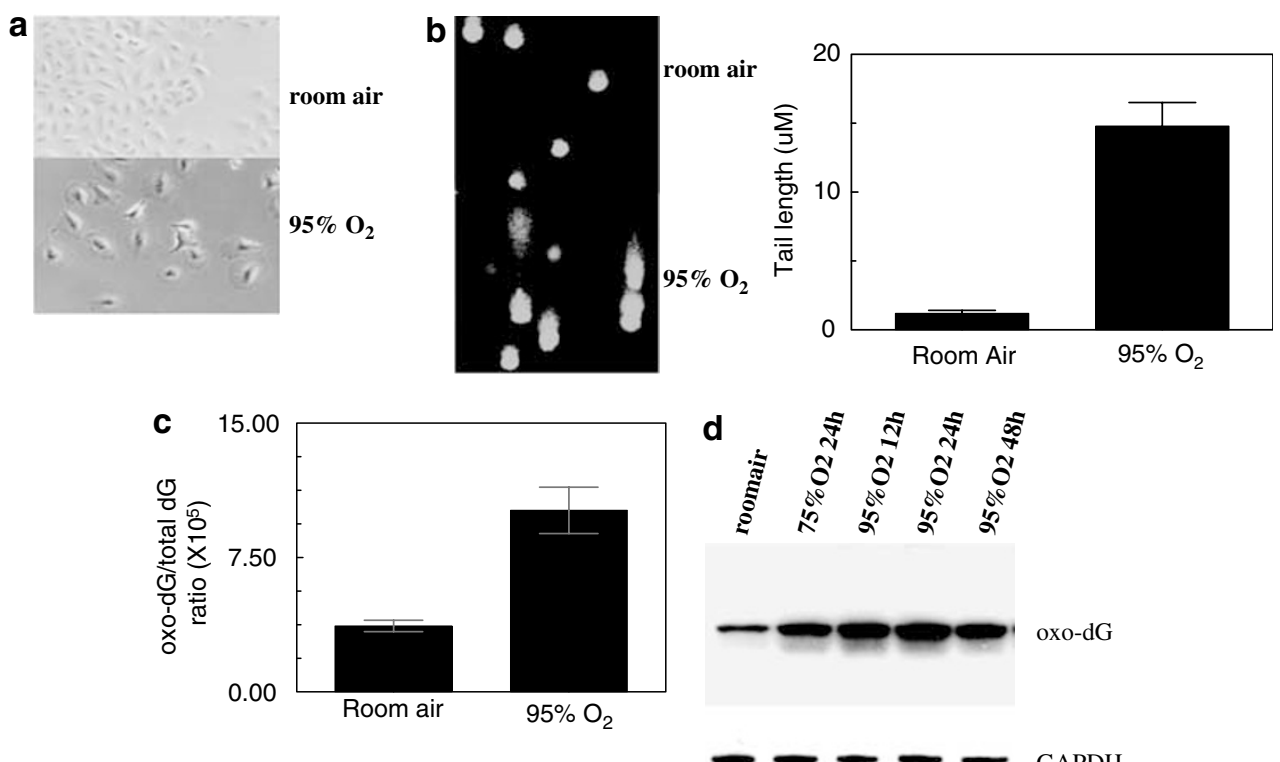

Figure 1 Hyperoxic injury to alveolar epithelial A549 cells. A549 cells were incubated in room air or $95 \%$ oxygen for $36 \mathrm{~h}$. (a) Morphologic damage assessed using light microscopy $(\times 400)$. The images demonstrate that hyperoxia altered cellular structure and significantly reduced cell number. (b) DNA strand breaks detected by a comet assay by measuring tail length by confocal fluorescence microscope. The assay demonstrated that average of tail lengths was markedly increased by hyperoxia in the lung cells compared to the control $(P<0.001)$. (c) Induction of 8-oxo-dG in A549 cells following hyperoxia exposure detected by HPLC-ECD. 8-oxo-dG, hallmark of oxidative DNA damage, is represented by arbitrary units (the ratio of oxo-dG to the total amount of dG, $10^{5}$ ). (d) Increase in 8-oxo-dG production also confirmed by Western blotting using antibodies specific for 8-oxo-dG. The amount of 8-oxo-dG is consistent with that determined by HPLC-ECD. Increase of 8-oxo-dG occurred at 12 $\mathrm{h}$ peaked at $48 \mathrm{~h}$ 
exposure using HPLC-ECD (Figure 1c). This increase in 8oxo-dG was further confirmed in nuclear extracts using Western blotting approach by monoclonal antibodies against 8-oxo-dG (Trevigen, Figure 1d). While the nuclear extracts were evenly loaded by reprobing with GAPDH and BCA assay, the increase of 8-oxo-dG is approximately three- to four-fold compared with the control. Western blotting using antibodies demonstrates compatible results to the HPLCECD method, but is more conveniently performed. The production of DNA 8-oxo-dG adduct is dependent on the hyperoxic intensity and the exposure time (peaked at $48 \mathrm{~h}$ ).

To study the effect of hOgg1 overexpression on hyperoxic toxicity, we have made a retroviral construct that successfully delivered hOgg1 into A549 lung cells. The cells initially expressed about $40 \%$ EGFP but expressed >99\% EGFP after two cycles of FACS sorting and colony selection. In addition, the selected cell clones expressed high levels of hOgg1, but to varying quantities in different clones. As shown in Figure 2a, clone 2 is a representative of total 35 clones overexpressing EGFP. Expression of hOgg1 was demonstrated by Western blotting detection in seven representatives of total 35 clones (Figure 2b). Overexpression of hOgg1 was also demonstrated by Northern, RT-PCR and enzymatic activity as shown previously. ${ }^{5}$ Colony forming units (CFU) and MTT assays ( $48 \mathrm{~h}$ ) were performed to determine whether cells could survive and resume proliferation following exposure to hyperoxia. ${ }^{5}$ As expected, overexpression of hOgg1 in A549 clones alleviated the toxicity of hyperoxia versus the control. ${ }^{5}$ Primary AECII cells were also transfected with hOgg1 using liposome reagent; transfection efficiency was approximately $32 \%$ but neomycin selection achieved approximately $81 \%$ positivity of hOgg1 expression determined by cytochemistry.

a

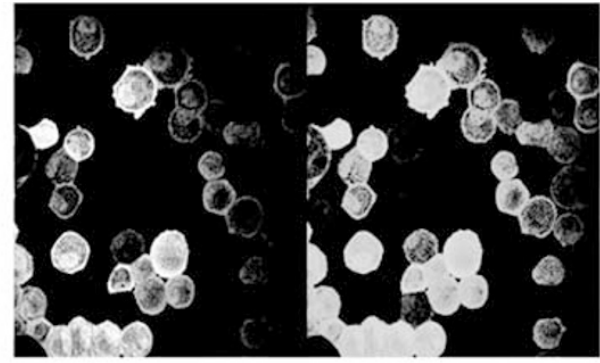

b

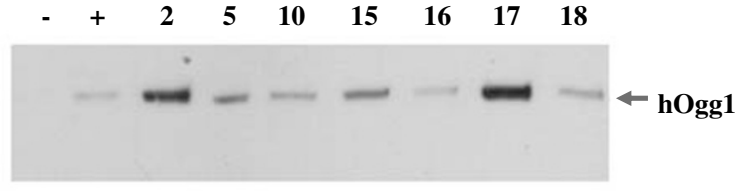

C

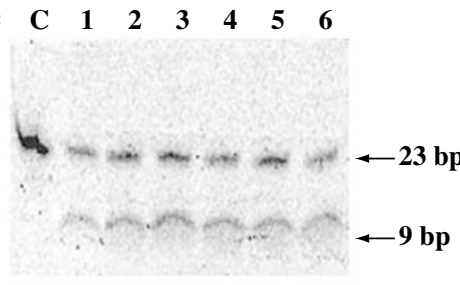

$\begin{array}{llllllll}\text { d } & \text { C } & 1 & 2 & 3 & 4 & 5 & 6\end{array}$
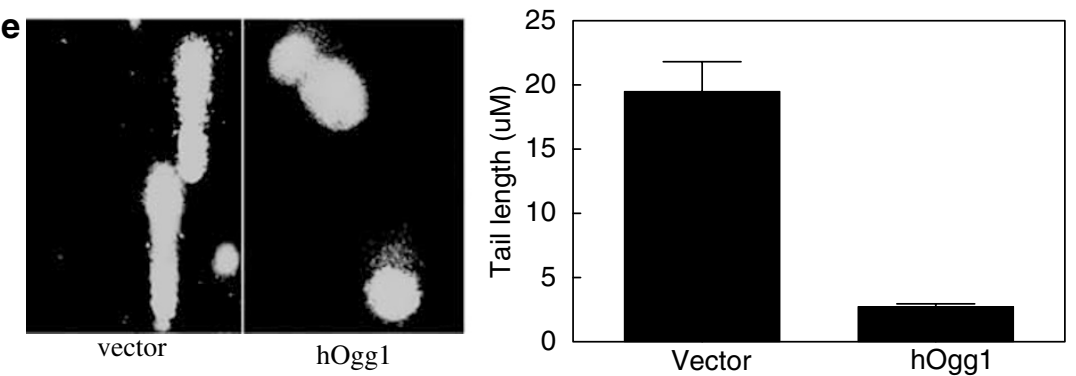

Figure 2 Transduction of hOgg1 in lung epithelial cells. (a) High levels of hOgg1 expression in A549 cells transduced by retroviral pSF91 vector (clone 2, see b). (b) Various levels of hOgg1 expressions in selected clones determined by Western blotting analysis. -, negative control (nontransduced A549 cells); +, positive control (previously transduced 3T3 cells); 2, 5, 10, 15, 16, 17 and 18, transduced A549 clones grown from a single colony. The hOgg1 is a $39 \mathrm{kDa}$ protein. (c) Various enzymatic activities of transfected AECII populations expressing hOgg1. Number 2-6 are different transfection populations with various levels of hOgg1 expression against vector controls. (d) Increased expression of hOgg1 in transfected AECII cells as shown by Western blotting, all samples (different populations) showed elevated levels of hOgg1 protein compared to vector control cells. (e) Decrease in hyperoxic DNA damage in primary lung cells overexpressing hOgg1 as determined by the comet assay, derived from averaged calculation of 75 cells 
Cell lysates were assayed for hOgg1 expression by enzymatic cleavage assay (Figure 2c) and Western blotting (Figure 2d). For activity assay, number 2-6 were different transfection populations and all showed significant hOgg1 expression. More importantly, overexpression of hOgg1 attenuated the hyperoxic toxicity in AECII cells against the vector controls as evidenced by reduced DNA strand breaks using a comet assay (Figure 2e). After exposure to hyperoxia for 2 days, the average of tail lengths in 75 cells overexpressing hOgg1 was $2.75 \pm 0.2 \mu \mathrm{m}$ (arbitrary), while $19.5 \pm 2.3 \mu \mathrm{m}$ in control cells $(P<0.01)$.

\section{hOgg1 on p38 activation induced by hyperoxia}

Although previous studies demonstrated that p38 activity is associated with nitrogen oxide and other oxidants, ${ }^{22,25,44}$ no direct evidence has shown a particular link of p38 to hyperoxic toxicity in lung epithelial cells. In this study, cells expressing hOgg1 or vector control were exposed to room air or hyperoxia for $36 \mathrm{~h}$. Phosphorylated p38 was quantitatively measured using phospho-ATF-2 Thr71 antibody in A549 cells after immunoprecipitation with immobilized phospho-p38 antibodies (Thr180/Tyr182). The results show that hyperoxia induces a seven-fold increase in p38 activity (determined by densitometry) compared to the control by hyperoxic exposure (Figure 3a). We then examined whether p38 is altered by enhanced expression of BER DNA repair proteins. The results suggest that overexpression of hOgg1 in A549 cells significantly decreases p38 activity under oxygen treatment (p38 activity was only half of those cells without transduction or vector transduction as determined by densitometry, $P<0.05$ ) (Figure 3b).

\section{Reduction of hyperoxic toxicity by chemical blocking and dominant-negative mutant of p38}

A chemical knockdown strategy was used to investigate if MAPK directly affect hyperoxic damage. p38 activity in A549 cells was assayed after exposure to $95 \% \mathrm{O}_{2}$ for $36 \mathrm{~h}$ using kinase analysis. p38 MAP kinase activity was decreased by p38 inhibitor SB202190 (Calbiochem, San Diego, CA, USA), confirming a specific upregulation by hyperoxia. The results demonstrate that p38 inhibitor specifically reduced p38 kinase activity (Figure 3c). We then examined whether SB202190 and hOgg1 can have added effect on decrease in p38 activity, our data indicate an apparent synergistic effect between hOgg1 and SB202190. To further assess whether the MAPK is specifically upregulated by hyperoxia, we have used several dominant-negative constructs to transfect the lung cells. An example is the transfection of p38 dominant-negative mutant (p38 $\alpha \mathrm{FA}$ ) using liposome Gene-Porter, we have demonstrated a downregulation of $\mathrm{p} 38$ activity, resulting in a reduced effect of hyperoxia-stimulated p38 kinase activity (Figure 3d). Transfection efficiency with the dominant constructs was approximately $37 \%$, but neomycin selection achieved over $83 \%$ cells expressing the inserted constructs by immunohistochemistry (not shown). Importantly, introduction of dominant-negative mutation ( $p 38 \alpha A F$ ) resulted in reduction of apoptosis in A549 cells under hyperoxic exposure for $48 \mathrm{~h}$
(Figure 3e). The result show that the mitochondrial component staining (CMXRos MitoTracker) appeared in the nuclear compartment along with the Annexin- $\mathrm{V}$ staining (apoptotic cells), but no Annexin- $V$ staining in the cell expressing p38 $\alpha$ AF. The apoptotic cells were enumerated and transfection with $\mathrm{p} 38 \alpha \mathrm{AF}$ construct resulted in less apoptosis compared to the vector control $(P<0.05)$. Similarly, we transfected freshly isolated AECII with p38 $\alpha \mathrm{AF}$ construct, which demonstrates significant protection against hyperoxia compared to the vector control in the primary isolation (Figure $3 f)$. The introduction of $p 38 \alpha \mathrm{AF}$ dominant-negative mutant also reduced the $\mathrm{p} 38$ activity compared with the vector control as determined by Western blotting (not shown).

\section{Beneficial roles by hOgg1 induced ERK1/2 activation}

Past studies have shown that hyperoxia induces ERK1/2 activity in the lung ${ }^{26}$ or in alveolar macrophages. ${ }^{44}$ In this report, we investigated whether hyperoxia activates ERK1/2 in freshly isolated AECII cells and A549 cells, and whether overexpression of BER proteins can modulate ERK1/2 activity. Using ERK1/2 kinase assay, we demonstrate that ERK1/2 activity was increased by two-fold following hyperoxic treatment of A549 cells (Figure 4a). AECII cells were isolated and identified by tannic acid staining, cytokeratin 18 and surfactant protein- $C$ immunostaining, and hyperoxia induced approximately two- $(48 \mathrm{~h})$ to three-fold $(24 \mathrm{~h})$ upregulation in ERK1/2 in primary AECIl cells (Figure 4b). The data suggest an upregulation of ERK1/2 pathway in both alveolar cell line A549 and primary alveolar cells under a natural response to hyperoxia. Comparing ERK1/2 activity between A549 and AECII cells, the results demonstrate that there was more significant increase of ERK1/2 in A549 cells than that in AECII cells.

We then transfected the AECIl cells to overexpress hOgg1 using GenePorter (Gene Therapy System). Levels of hOgg1 overexpression were compared in transduced A549 and AECII cells, and the results suggest that A549 cells expressed approximately two-fold hOgg1 than that of AECII cells. We also show that overexpression of hOgg1 markedly induced the activation of ERK1/2 (15-fold against the control, Figure 4c). Protein loading was controlled using Bio-Rad or BCA protein assay and also normalized by total ERK1/2 proteins. Furthermore, A549 cells overexpressing hOgg1 were associated with decreased hyperoxic toxicity and increased cell survival against vector control cells as determined by a trypan blue exclusion assay $(P<0.05$, Figure 4f). We also confirmed the results using the MTT assay showing that proliferation was increased by hOgg1 (not shown). This is consistent with a previous study that demonstrated the protective role of ERK $1 / 2$ against hyperoxia. ${ }^{26}$ To further confirm the above observations, we used the ERK inhibitor PD98059 to test hyperoxic regulation of ERK1/2 activity. The addition of the chemical inhibitor resulted in significant reduction of ERK $1 / 2$ activity in comparison with the controls upon oxygen exposure (Figure 4e). However, reduction of ERK1/2 by PD98059 inhibitor significantly increased hyperoxic toxicity and decreased cell survival 
a

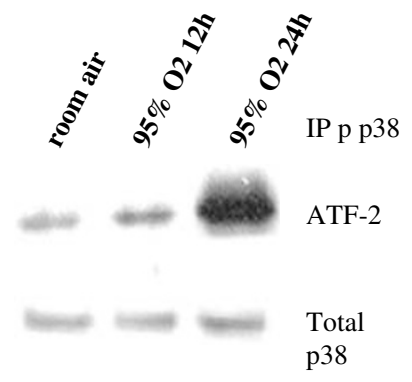

c

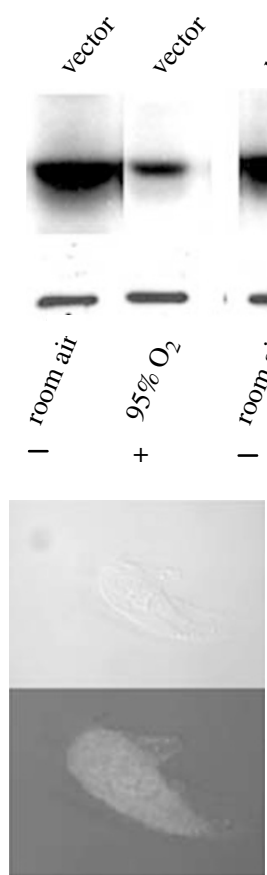

control

e

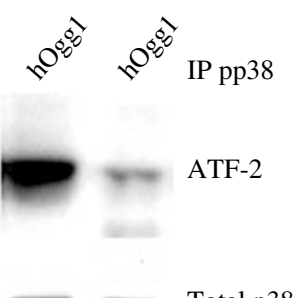

$a^{2}$

+ Inhibitor b

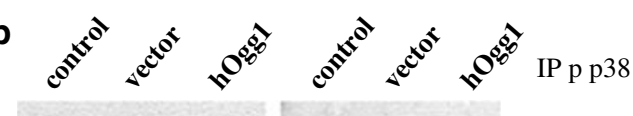

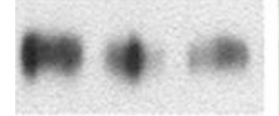

$0 \times$

ATF-2

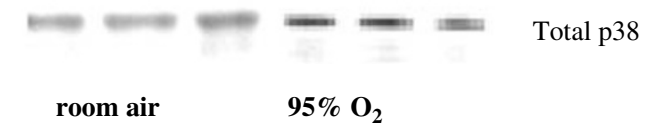

d
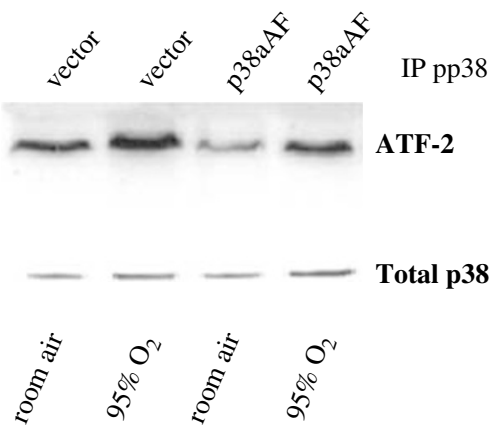
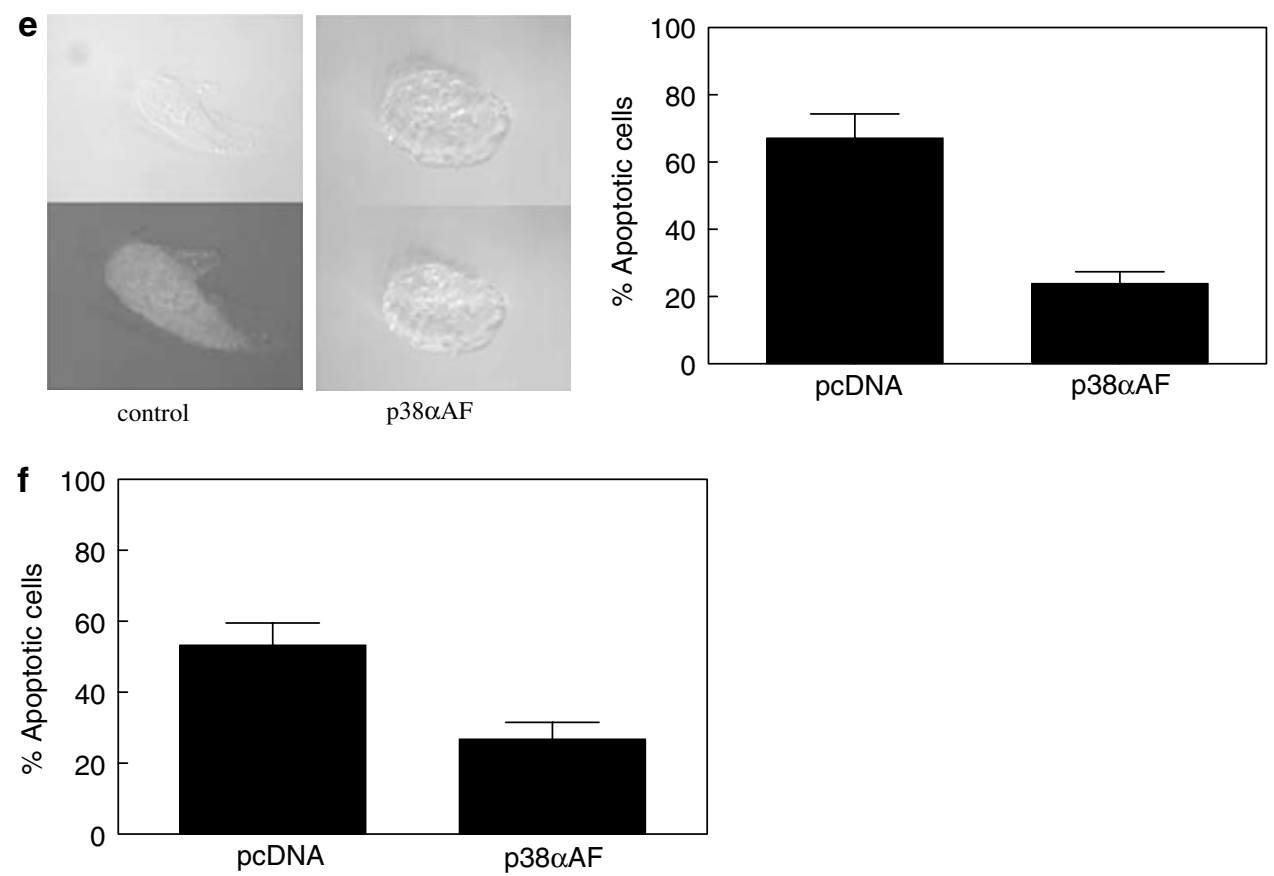

Figure 3 Reduction of $\mathrm{p} 38$ activity by BER correlating to decreased hyperoxic damage. (a) Activation of $\mathrm{p} 38$ in A549 cells by hyperoxia. A549 cells were incubated in room air or $95 \% \mathrm{O}_{2}$ for $24 \mathrm{~h}$ before immunoprecipitation with phospho-p38 (Thr180/Tyr182) antibody. Phosphorylated p38 was measured by phospho-ATF-2 (Thr71) antibody using p38 kinase assay as per the manufacturer's instructions. (b) Inhibition of p38 activity by hOgg1 overexpression following hyperoxia for $24 \mathrm{~h}$. Control, no treatment; vector, A549 cells expressing only the vector; hOgg1, A549 cells expressing hOgg1 (clone 2). (c) Inhibition of p38 activity by p38 inhibitor SB202190 (Calbiochem). p38 inhibitor was added to A549 cells for 30 min before exposure to hyperoxia for $24 \mathrm{~h}$. p38 activity was then measured as above. (d) Inhibition of p38 activity by transfection of dominant-negative construct p38 $\alpha \mathrm{AF}$. The transfected cells or vector controls were incubated in room air or in $95 \%$ oxygen for $24 \mathrm{~h}$ and p38 activity was determined as above. Compared to controls, transfection of dominant-negative constructs resulted in less p38 activity in A549 cells in room air as well as in $95 \%$ oxygen. (e) Reduced apoptosis of cells expressing p38 $\alpha \mathrm{AF}$ compared to the pcDNA vector control. Mitochondrial component staining was carried out with CMXRos MitoTracker at $5 \mathrm{nM}$, while nuclear compartment in apoptotic cells was determined by Annexin-V staining. We counted a total of 100 cells per sample and mitochondrial damage was shown as percentage of apoptosis. The data show a significant decrease in mitochondrial damage in cells expressing p38 $\alpha \mathrm{AF}$ compared to control with pcDNA vector. (f) Reduced apoptosis of AECII cells expressing p38 $\alpha \mathrm{AF}$ against control with the pcDNA vector. The method is as described in (e)

against control cells as determined by a trypan blue exclusion assay $(P<0.05$, Figure $4 \mathrm{f})$. We also confirmed the results using the MTT assay showing that proliferation was decreased by the inhibitor (not shown). These data indicate that ERK $1 / 2$ is involved in protection of alveolar epithelial cells against hyperoxic toxicity. 
a

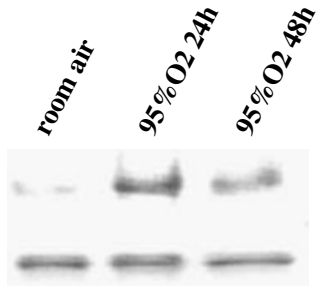

C

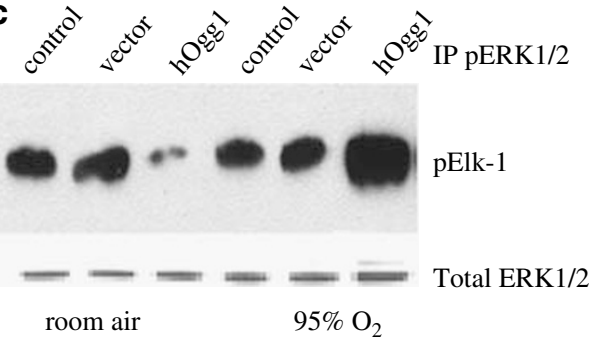

e

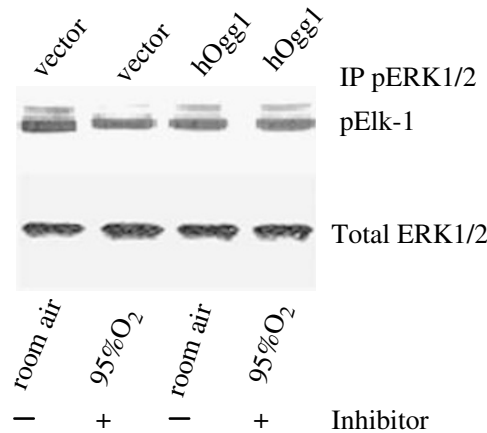

b
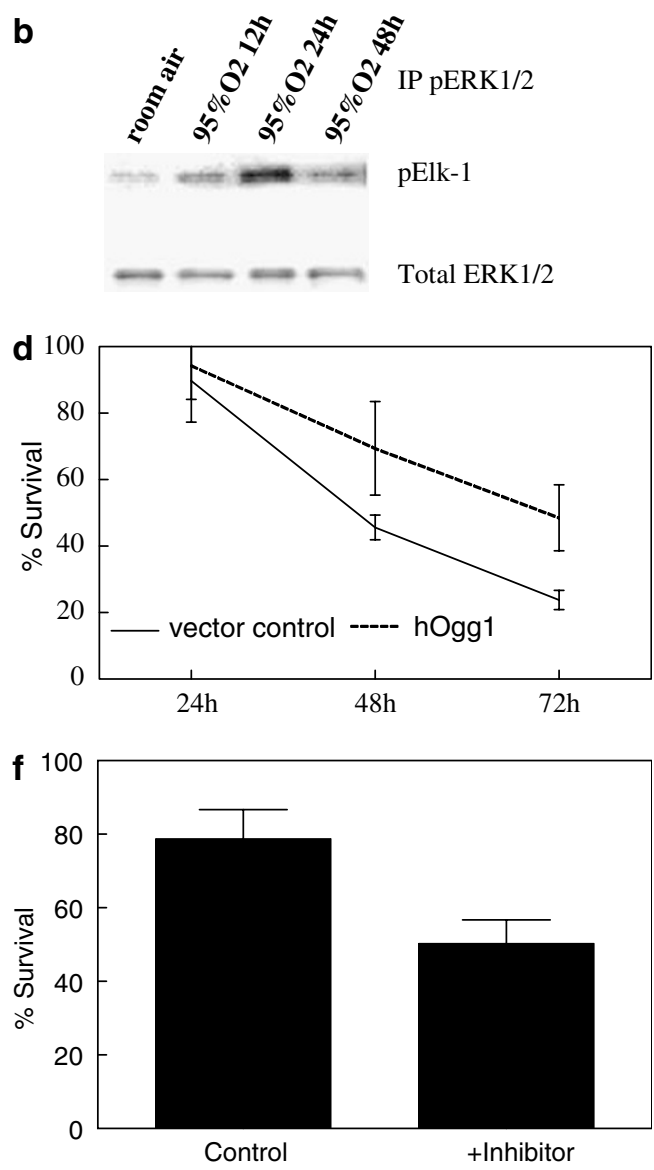

Figure 4 Increase in ERK1/2 MAP kinase activity by overexpressing hOgg1. (a) Activation of ERK1/2 in A549 cells by hyperoxia using ERK1/2 kinase assay. A549 cells were incubated in room air or $95 \% \mathrm{O}_{2}$ for $24 \mathrm{~h}$ before immunoprecipitation with phospho-ERK1/2 (Thr202/Tyr204) antibody. Phosphorylated ERK1/2 was measured by pElk-1 antibody using ERK $1 / 2$ kinase assay as per the manufacturer's instructions. (b) Activation of ERK $1 / 2$ in primary AECII cells by hyperoxia using ERK $1 / 2$ kinase assay. AECll cells were incubated in room air or $95 \% \mathrm{O}_{2}$ for $24 \mathrm{~h}$ before being assayed as above. (c) ERK $1 / 2$ activity was further increased by overexpression of $\mathrm{hOgg} 1$ in AECII cells. AECII cells were prepared by the method described previously. ${ }^{31,59} \mathrm{AECll}$ cells expressing hOgg1 ( $24 \mathrm{~h}$ after transfection) were exposed to hyperoxia for $24 \mathrm{~h}$. ERK1/2 MAPK activity of control and transfected cells was determined as above. (d) Reduction of hyperoxic toxicity correlates with increase of ERK1/2 kinase activity in A549 cells overexpressing hOgg1 (clone 2). Survival of cells overexpressing hOgg1 was determined by a trypan blue exclusion assay compared to the vector control under hyperoxia (48 h). (e) Blocking of the ERK1/2 activity by specific MEK/ERK1/2 inhibitor PD98059 (Cambiochem) for 30 min before exposure to $95 \%$ oxygen. (f) Inhibition of ERK1/2 kinase activity by inhibitor PD98059 aggravated hyperoxic toxicity in A549 cells (48 h). The results of a trypan blue exclusion assay demonstrated decreased cell survival under hyperoxia compared to the control

\section{Induction of apoptosis by hyperoxia}

Whether or not hyperoxia causes significant apoptosis is a controversial topic. Until very recently, there was no report to demonstrate caspase-mediated apoptosis in animals by hyperoxia. ${ }^{45}$ Apoptosis was identified by Vybrant Apoptosis Assay (Molecular Probes), which showed that the apoptosis was reduced by overexpression of hOgg1 (green dye staining apoptotic cells, while red dye staining necrotic cells, Figure 5a). Control A549 cells expressing vector had $40 \%$ apoptotic cells (green color), while transduced cells expressing hOgg1 had virtually no apoptosis ( $<5 \%$, similar to room air control) by quantitative assessment (Figure 5b). Our data indicate that overexpression of hOgg1 in A549 cells reduced hyperoxic apoptosis compared with the vector control. hOgg1 may interact with cell survival signaling pathways to reduce hyperoxia-induced apoptosis. To ascertain the results, apop- tosis was determined by Death ELISA assay to measure the nucleosomal DNA fragments and the results showed that overexpression of hOgg1 significantly reduced apoptosis from hyperoxic exposure (Figure 5c). Other assays such as TUNEL and DNA laddering also demonstrate the similar results (data not shown). Taken together, these data indicate the protection role of hOgg1 in lung epithelial cells through attenuating apoptosis, and support our hypothesis that hyperoxia regulates both MAPK and hOgg1.

\section{Hyperoxia induces p21 and p53 signaling pathways}

Having found apoptosis following hyperoxia exposure, we investigated how this response is initiated and regulated. We assessed whether hyperoxia can increase levels of p53 or 
a
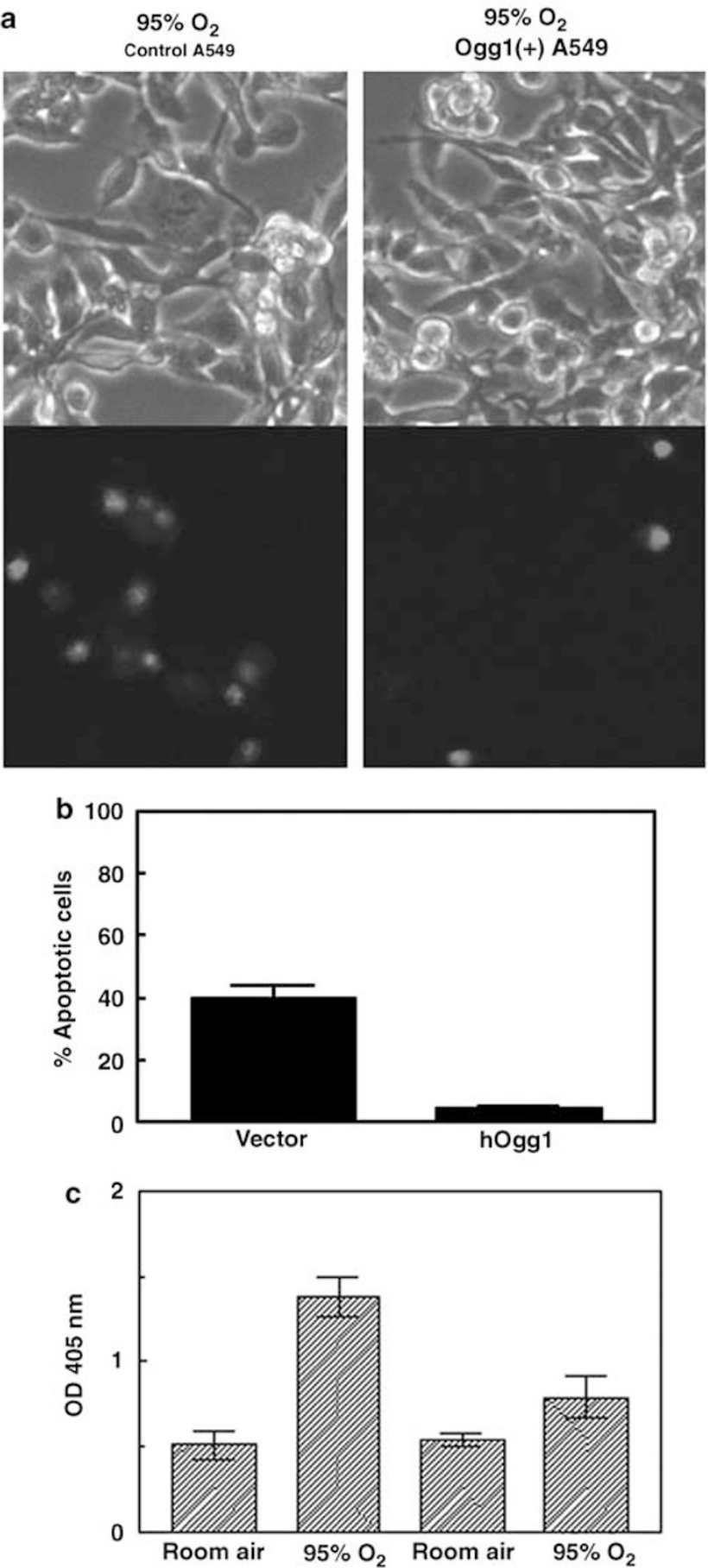

Figure 5 Attenuation of apoptotic death by overexpression of hOgg1 in A549 cells. (a) Overexpression of hOgg1 resulted in reduced apoptosis by hyperoxia against the control. Apoptosis in A549 cells expressing hOgg1 or vector control was determined by Vybrant Apoptosis Assay (Molecular Probes) (48 h). Green dye (YO-PRO-1) indicates apoptotic cells, while red (propidium iodide) showing necrotic cells. (b) Bar graph showing the apoptotic data in (a). Approximately $40 \%$ cells have apoptosis treated by hyperoxia in vector control, while less than $5 \%$ cells have apoptosis in cells overexpressing hOgg1 $(P<0.05)$. (c) Inhibition of hyperoxic apoptosis by overexpression of hOgg1 as determined using Death ELISA assay. The Death ELISA Apoptosis Assay was performed according to the manufacturer's instruction ( $48 \mathrm{~h})$ p21. Despite not being a lung cell line, p21 deficient cell lines (HCT116 p21 ${ }^{-/-}$) cells are well-established model of p21 knockout that does not need to further establish and characterize the p21 deficiency. ${ }^{33}$ We detected significantly reduced levels of ERK1/2 (half of the control) in HCT116 p21 ${ }^{-1-}$ cells compared with the parental HCT116 cells when exposed to hyperoxia $(36 \mathrm{~h})$, suggesting that HCT116 p21 $1^{-/-}$ cells were particularly sensitive to hyperoxic toxicity, consistent with previous reports. ${ }^{19}$ For the gel, consistent loading of samples was ensured by BCA protein assay (Figure 6a). In addition, we have found that hyperoxia induced cell cycle arrest, but hOgg1 expression reduced this arrest by flow cytometry (not shown). We then studied p53 and p21 activation in A549 cells in hyperoxia using semiquantitative RT-PCR. The results demonstrate that transcripts of p21 were markedly upregulated by hyperoxia (Figure $6 \mathrm{~b}$ ) against control (from undetectable to strong band at 24 and $48 \mathrm{~h}$ ) in a dose-dependent manner. mRNA transcripts of p53 were also increased against the control (increase by four-fold at $48 \mathrm{~h}$; Figure $6 \mathrm{~b}$ ). Both sets of RT-PCR results were examined by GAPDH as the internal control, which showed no difference in sample loading.

We next determined whether p53 is regulated by hyperoxia at post-transcriptional levels by Western blotting. Our results revealed that $\mathrm{p} 53$ phosphorylation was activated by hyperoxia as determined using specific antibodies against the site of Ser37 and Ser392. The results showed that increased phosphorylation at Ser37 (three-fold increase at $48 \mathrm{~h} 95 \%$ oxygen) (Figure 6c). Ser392 of p53 was also shown a two-fold increase at $12 \mathrm{~h} 95 \%$ oxygen compared with the control (not shown). The above data indicate that both p53 and p21 may be associated with MAPK activity upon hyperoxic toxicity. Since above results also indicate that apoptosis was involved in hyperoxia, thus p21 may have a protective role in hyperoxic DNA damage. Finally, we dissected whether BER affected p21 or p53. Our results indicate that overexpression of BER hOgg1 increased p21 and p53 activity compared with the vector controls. However, p21 induction was not dependent on p53 (data not shown). Taken together, BER proteins may have an interaction with p21 and p53. It is still unclear whether p21 is a result of the upregulated p53. Finally, we have also revealed a three-fold increase in phosphorylation of CDC2 at Thr161 after $48 \mathrm{~h}$ 95\% exposure (Figure 6d). Since the CDC2cyclin B heterodimers act to trigger all the major events of mitosis, hyperoxia may induce both death and living signaling in damaged cells. The fate of the cell will eventually be decided by the balance and interaction of the complex signaling pathways, particularly BER and MAPK along with p53 and p21 (Figure 7 for the hypothetic pathway during hyperoxic injury).

\section{Discussion}

In this report, we demonstrate an association of the damaging effects of hyperoxia with alterations in p38 and ERK1/2. Our report also reveals an association between MAPK and BER proteins as a response to hyperoxic damage in A549 cells and primary AECII cells. This observation is based on the fact that overexpression of the BER hOgg1 attenuated the hyperoxia 
a

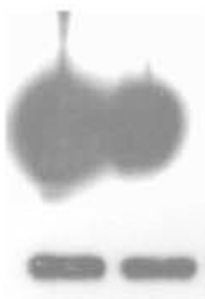

$21 \% 95 \% \mathrm{O}_{2}$ p21 cells

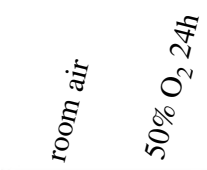

$21 \% 95 \% \mathrm{O}_{2}$ p21/-cells

\section{Total}

ERK1/2

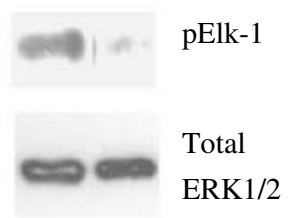

IP pERK1/2

Elk-1

2
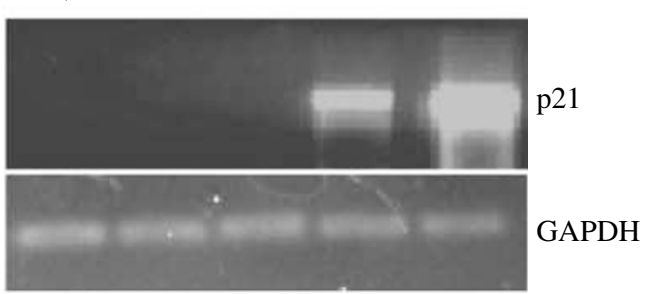

b
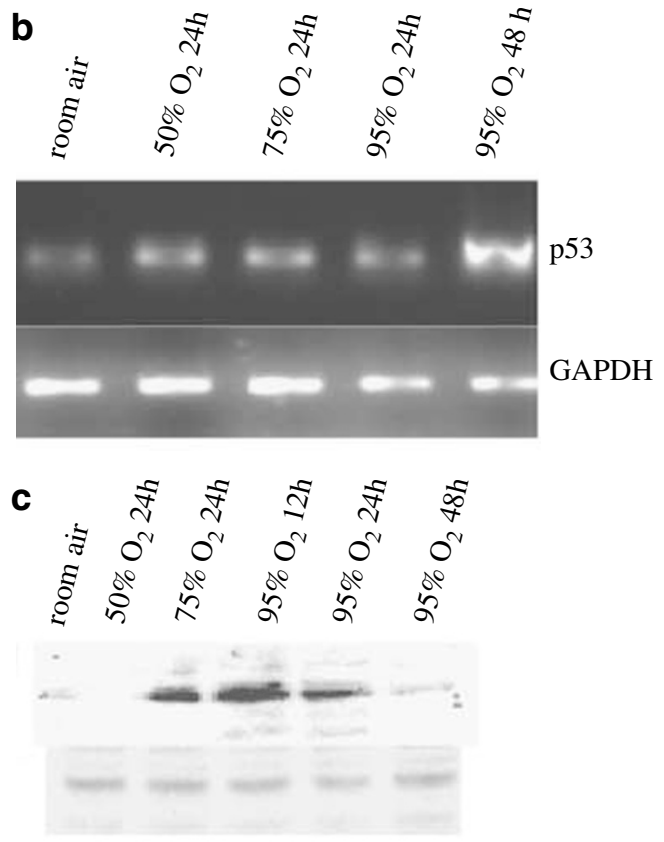

d

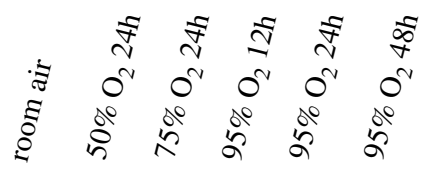

CDC2 Thr161

GAPDH
Hypothetical pathway of hyperoxia induced DNA damage and repair

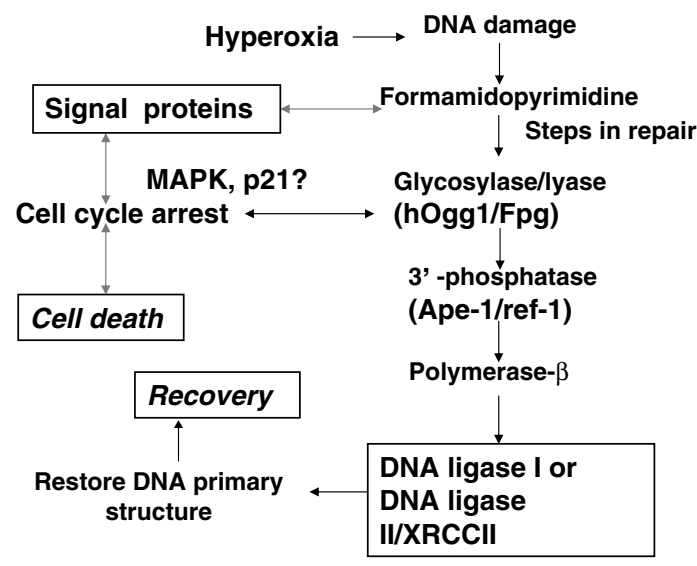

Figure 7 Hypothetic signaling pathways involved in hyperoxic toxicity. This schematic diagram outlines our hypothetic model of a possible interaction of MAPK with BER DNA repair pathway. The interaction plays a pivotal role in de ciding the fate of the stressed cells: either cycle arrest (death) or DNA repair (recovery)

toxicity while with altered MAPK activity. This indicates that BER gene products may reduce DNA damage related to MAPK activity. Further experiments suggest that apoptosis was induced while reduction in p38 and increase in ERK $1 / 2$ alleviates the toxicity. Previous reports have indicated that oxidative stress can regulate MAPK through mismatch DNA repair pathways. ${ }^{28}$ To our knowledge, this study is the first to show such a mechanism by which hyperoxia-induced MAPK activity may be associated with the BER pathway. Our study also suggests that different MAPK may have distinct roles in response to hyperoxic toxicity.

Although it has long been linked to chromosome alterations by hyperoxia, ${ }^{1}$ little is known about the molecular mechanism of hyperoxia-induced DNA damage to AECII cells until recently. ${ }^{5,9}$ We here revealed that hyperoxia induced 8-oxodG lesions in lung cells, a common adduct induced by a variety of oxidants. Besides the conventional method of HPLC-ECD to measure 8-oxo-dG, we have examined the possibility of Western blotting to detect 8-oxo-dG. It is convenient to use Western blotting, and our results showed consistent quantity of 8-oxo-dG determined by the conventional method HPLC-ECD. Repair of 8-oxo-dG is required as

Figure 6 Cell signaling proteins in regulating MAPK during hyperoxia. (a) Increased sensitivity towards hyperoxia in $\mathrm{p} 21^{--}$cells. Cells were incubated in room air or $95 \%$ oxygen and ERK1/2 kinase was measured using Western blotting as Figure 4. ERK1/2 activity was decreased in p21 $1^{-1-}$ cells accompanied with severe toxicity. (b) Increase in mRNA of p21 and p53 during hyperoxia in lung cells was determined by semiquantitative RT-PCR after 30 cycles (Materials and Methods). Expression of p53 and p21 mRNA was dependent on both exposure time and the intensity of hyperoxic conditions. (c) Upregulation of p53 at post-transcriptional levels. Phosphorylation of p53 at Ser37 was shown by Western blotting assay by exposure to hyperoxia for various times. (d) Phosphorylation of CDC2 at Thr161 was increased depending on exposure time and intensity of hyperoxia. This was determined using Western blotting by antibodies from Cell Signaling Technologies 
this lesion may result in mutations or significant toxicity; for lung cells, the toxicity is of a major concern.

DNA repair proteins, especially, BER can effectively repair 8-oxo-dG lesion initiated by hOgg1. hOgg1 can alleviate oxygen-induced DNA damage by removing the modified 8-oxo-dG on the DNA through glycosylase activity. ${ }^{5}$ We now show that the DNA glycosylase hOgg1 was able to significantly reduce hyperoxia induced DNA damage and cytoxicity. In addition, hOgg1 overexpression seemingly involves MAPK activity in both cultured cell line A549 and primary AECII cells. MAPK participate in diverse cellular functions including cell proliferation, transformation, and differentiation. ${ }^{22,23,46}$ MAPK p38 $\alpha$ was significantly activated by hyperoxia; inhibition of p38 $\alpha$ using dominant-negative construct reduced the toxicity of hyperoxia. However, this study cannot exclude other p38 isoforms that are involved in hyperoxia induced G2 arrest. Furthermore, significant inhibition of p38 demonstrates reduction in apoptosis determined by Vybrant and Death ELISA assays. The medical significance is that perturbation of p38 may be useful tool to reduce hyperoxic toxicity in lung cells.

Our observation also revealed that ERK1/2 was involved in hyperoxic toxicity. Previously, it has been indicated that ERK1/2 may contribute to protection against hyperoxia toxicity. Consistent with this finding, our data demonstrate that ERK1/2 was slightly increased under oxygen stress. However, overexpression of BER hOgg1 markedly increased ERK1/2, thereby decreasing the ensuing toxicity of hyperoxia. Not only did we observe changes in ERK1/2 kinase activity but also we found that DNA damage is reduced in a dosedependent manner.

Thus, this study not only revealed the important role of MAPK and BER in response to hyperoxia, but also indicated an association between the two different classes of proteins. BER proteins have not been reported to be directly associated with cell proliferation and cell growth that are the main functions of some MAPK. BER proteins are critical to repairing oxidant DNA lesions, particularly the 8-oxo-dG adduct. However, DNA damage repair might participate in regulation of cell growth or proliferation by interacting with other cell signaling proteins under oxidative stress. hOgg1 is expressed on many cell types, ${ }^{47}$ but can be depleted by oxidative damage like chemical carcinogens. ${ }^{20,48}$ Therefore, hOgg1 plays a potential role in homeostasis of the cell; ${ }^{47}$ indeed, frequent mutations of hOgg1 are associated with a variety of tumors. ${ }^{49-51}$ Overepxression of hOgg1 has been shown to reduce toxicity of chemotherapeutics or other stresses by several groups. ${ }^{5,13,52}$ No untowards effects, such as increased apoptosis of the cells, have been found when hOgg1 is overexpressed up to 3 years with retroviral vectors ( $\mathrm{Wu}$ et al., unpublished).

Previous studies have indicated that p21 deficient cells manifest strong toxicity following hyperoxia treatment. ${ }^{19}$ This indicates that cell cycle arrest may not be initiated or reversed in p21 deficient cells. Also, lack of BER gene expression is associated with increased toxicity during hyperoxic exposure. To evaluate the downstream signals in the MAPK pathway, our data indicate that hyperoxia can induce p21 mRNA expression, depending on the intensity of hyperoxic toxicity. We also demonstrated that p21 deficient cells were more sensitive to hyperoxia treatment associated with a decrease in ERK1/2 activity, consistent with previous observations. ${ }^{19}$ Thus, regulation of $\mathrm{p} 21$ may be related to ERK1/2 expression and activation, which may be crucial for reducing hyperoxic toxicity.

Furthermore, we have found that p53 was upregulated and activated by hyperoxia treatment at the transcriptional level. The increase in p53 was the reason of inducing a G2 cell cycle arrest. BER intermediates are reported to induce p53independent cytotoxic and genotoxic responses; ${ }^{53}$ thus, it is unclear whether hyperoxia can induce p53-dependent genotoxic responses. Previous reports have shown that p53 can be phosphorylated at the Ser392 by UV, but not by ionizing radiation. ${ }^{54}$ This study demonstrates that the regulation of p53 was also at the post-transcriptional level, with p53 phosphorylation occurring at several sites including Ser37 and Ser392. Previously, only phosphorylation at Ser15 was reported to be related to hyperoxic activation. Therefore, this study has provided novel insights into the molecular mechanism of hyperoxia.

We have also revealed an increase in phosphorylation in CDC2 at Thr161. This is an interesting finding, since the CDC2-cyclin B heterodimers act to trigger all the major events of mitosis ${ }^{55}$ and inhibition of this protein kinase is sufficient to prevent mitotic entry. However, it is still unclear why CDC2 Thr161 is activated. It may be a result of mixed regulation between MAPK and p53/p21. The balance should be ensured by appropriate responses (Figure 7 representing a model of interactive signaling under hyperoxia). Without repair of damaged DNA, severe hyperoxic toxicity would consume all the protective mechanisms, resulting in unavoidable apoptotic or necrotic cell death.

We have not performed in vivo experiments to further confirm the above observations in the present paper. In vivo studies may be more complex since the conditions and regulations are not simply controlled by one single factor. In addition, previous studies already indicate discrepancies whether hyperoxia causes apoptosis or necrosis in vivo and in vitro, even in different species of animals. ${ }^{10,26,45,56,57}$ Furthermore, isolation and transfection of AECII cells may contribute to complex factors due to the dedifferentiation of the AECII cells in vitro and the difficulty to transduce foreign genes in these cells. ${ }^{58}$ Nevertheless, our experiments derived from A549 cells with the confirmation from AECII cells, for the first time, indicate possible cross-talks between the different two groups of functional proteins.

In summary, our studies revealed that BER DNA repair proteins were involved in MAPK activation, which suggests that these two distinct protein families may share some common roles in cell life programming. These studies provide new insight into cellular signaling pathways under hyperoxic toxicity, suggesting that alteration of MAPK may be a viable approach to reducing hyperoxic toxicity. Detailed interaction between BER and MAPK still remains to be elucidated. Future work may be undertaken to address whether hOgg1 directly regulates MAPK action. This may be achieved by investigating whether p38 and ERK act differently in the absence or in the presence of hOgg1. Further identification of the interaction may yield additional knowledge for the development of better treatment of hyperoxic toxicity. 


\section{Materials and Methods}

\section{Cell culture}

Human alveolar epithelial cell line A549 was obtained from ATCC and cultured in DMEM medium containing $10 \%$ newborn bovine serum (HyClone Laboratories, Logan, UT, USA), $100 \mathrm{U} / \mathrm{ml}$ of penicillin, and $100 \mu \mathrm{g} / \mathrm{ml}$ of streptomycin (Life Technologies, Rockville, MD, USA). The cells were allowed to adhere to the plates through $37^{\circ} \mathrm{C}$ overnight incubation, then the medium was replaced and cultured in $95 \% \mathrm{O}_{2}$. HCT116 (a colon cancer cell line), HCT116 p21 $1^{-1-}$ cells were kindly provided by $B$ Vogelstein ${ }^{33}$ and grown in McCoy's $5 \mathrm{~A}$ medium. Isolation and culture of rat $A E C I$ were performed using the methods reported previously. ${ }^{34} \mathrm{AECll}$ were isolated from Sprague-Dawley female rats by 'panning'. ${ }^{34}$ Yields were around $15 \times 10^{6} \mathrm{AECll}$ cells/rat and purity was around $90-95 \%$ after 1 day culture in plastics. Phenotypes of AECII were identified by three methods: (a) alkaline phosphatase staining, ${ }^{35}$ (b) tannic acid staining, and (c) surfactant protein (SP-C) determined by immunochemistry staining. ${ }^{36}$

\section{Models of hyperoxic exposure to cells}

Assessment of cell injury in vitro by hyperoxia was similar to previous studies from our laboratory. ${ }^{5,37}$ Cells were grown in DMEM medium and seeded on $6 \mathrm{~cm}$ dishes at a concentration of $8 \times 10^{4} \mathrm{celll} / \mathrm{ml}$. The next day, the cells were exposed to $95 \% \mathrm{O}_{2}-5 \% \mathrm{CO}_{2}$ for $12,24,48$ and $72 \mathrm{~h}$. Control cells were incubated in room air-5\% $\mathrm{CO}_{2}$ for the same time intervals. $\mathrm{O}_{2}$ concentrations were monitored with a mini Oxygen Ted 60T meter (Teledyne Analytical Instruments, City of Industry, CA, USA). $\mathrm{O}_{2}$ tension in medium was $647 \pm 9 \mathrm{mmHg}$ determined as previously described. ${ }^{38}$

\section{Western blotting and phosphorylation assays}

Western blotting was performed as described previously. ${ }^{39}$ Briefly, cell lysates were separated by SDS-PAGE (10\%), and then electroblotted to presoaked Immobilon-P membranes (Millipore, Bedford, MA, USA) for $18 \mathrm{~h}$ at $40 \mathrm{~mA}$ constant current in transfer buffer (192 mM glycine, $20 \mathrm{mM}$ Tris- $\mathrm{HCl}$, and $15 \%$ methanol). The membranes were blocked by soaking in $5 \%$ dry milk in TBS-T ( $50 \mathrm{mM}$ Tris- $\mathrm{HCl} \mathrm{pH} \mathrm{7.5,150} \mathrm{mM} \mathrm{NaCl}$ and $0.05 \%$ Tween-20) solution for $2 \mathrm{~h}$ at room temperature. Each blot was incubated with rabbit polyclonal antibodies to hOgg1 (Novus Biologicals, Littleton, CO, USA), p21, p53, ERK1/2 and p38 (Cell Signaling Technologies, Beverly, MA, USA) at a dilution of $1: 1000$ at $4{ }^{\circ} \mathrm{C}$ overnight. The membranes were briefly rinsed with deionized water, and then washed

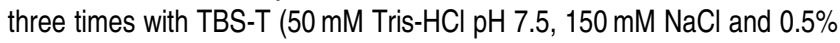
Tween-20) for $10 \mathrm{~min}$ per wash. Secondary anti-rabbit peroxidaseconjugated antibodies (Amersham, St. Louis, MO, USA) at 1:2000 were then added and incubated with the membrane at room temperature for $45 \mathrm{~min}$. Finally, the membrane was extensively washed as above and exposed on Kodak OMAT film using a chemiluminescence detection kit (Pierce, Rockford, IL, USA).

\section{MAP kinase activity}

p38 kinase activity was measured by immunoprecipitation with phosphoantibodies against p38 and anti-phospho ATF-2 at Thr71. ERK kinase activity was measured by immunoprecipitation with an antibody to phospho-ERK1/2 (Thr202 and Tyr204) and then by detection of MAPKinduced phosphorylation of Elk-1 (Cell Signaling Technology). The total proteins of ERK $1 / 2$ and p38 were also determined by Western blotting and ratios were calculated using averages of three experiments by measuring the mean density with Adobe Photoshop Software 7.0 (Adobe Systems Incorporated, San Jose, CA, USA). All the standard errors were less than $20 \%$.

\section{DNA damage assays}

DNA samples were treated with nuclease $\mathrm{P} 1$ and alkaline phosphatase as described $^{40}$ and analyzed for the presence of 8-oxo-dG by HPLCElectrochemical Detector LC-4B/17A (ECD) (Bioanalytical Systems, West Lafayette, IN, USA). 8-0xo-dG was also determined in nuclear extracts by Western blotting with 8-0xo-dG specific monoclonal antibodies as above (Trevigen, Gaithersburg, MD, USA). Briefly, nuclear extracts were prepared as described previously ${ }^{21,41}$ and consistent loading was controlled by measuring the protein concentrations using BCA assay as well as optical density at $260 \mathrm{~nm}$. The nuclear extracts were separated by $10 \%$ SDS-PAGE, transferred onto Immobilon-P membrane, and 8-oxo-dG was detected by monoclonal antibodies against 8-oxo-dG. The membrane was reprobed with GAPDH to check the sample loading.

\section{Comet assay}

The Comet assay was performed according to the manufacturer's instructions using a CometAssay kit (Trevigen). Briefly, after exposure of cells to hyperoxia or $\mathrm{H}_{2} \mathrm{O}_{2}$, cells were washed with $\mathrm{Ca}^{2+}$ - and $\mathrm{Mg}^{2+}$-free PBS at a concentration of $3 \times 10^{5} \mathrm{cell} / \mathrm{s} / \mathrm{ml}$. The cell suspension was mixed with liquefied agarose at a $1: 10$ (vol/vol) ratio. A small aliquot of this mixture was immediately transferred onto the slide provided. After celllysis at $4^{\circ} \mathrm{C}$, slides were treated with alkaline solution $(0.3 \mathrm{M} \mathrm{NaOH}, 1 \mathrm{mM}$ EDTA) for $60 \mathrm{~min}$ to unwind the double-stranded DNA. Slides were electrophoresed at $1 \mathrm{vol} / \mathrm{cm}$ for $10 \mathrm{~min}$. After staining with SYBR green dye, samples were visualized and photographed by fluorescent microscopy using an Olympus BX60 Microscope System and Paxit software (MIS, Franklin Park, IL, USA). Tail length was defined as the distance between the leading edge of the nucleus and the end of the tail as arbitrary units $(\mu \mathrm{m})$. A total of 75 determinations were made for each sample using Adobe Photoshop software (Adobe System Inc., San Jose, CA, USA). The experiments were repeated at least three times. The data were a representative of the three experiments.

\section{DNA repair activity assay}

The hOgg1 activity of transduced cells was quantified by detecting the cleavage of the 23-bp oligonucleotide substrate, containing a single 8oxoguanine lesion 5'-GAA-CTA-GTGOATC-CCC-CGG-GCT-GC-3' (Trevigen). Cell lysates from control cells and cells transduced with hOgg1 (10- $\mu \mathrm{g}$ protein samples) were reacted separately with $0.1 \mathrm{pmol}$ of $\gamma-\left[{ }^{32} \mathrm{P}\right] \mathrm{dATP}$ end-labeled 23 -bp substrate at $37^{\circ} \mathrm{C}$ for $1 \mathrm{~h}$ in $150 \mu \mathrm{l}$ of analysis buffer $(10 \mathrm{mM} \mathrm{N}$-2-hydroxythylpiperazine- $N$-2-ethane sulfonic acid-KOH, pH 7.4, $10 \mathrm{mM} \mathrm{KCl,} 10 \mathrm{mM}$ ethylenediamine tetraacetic acid (EDTA), and $0.1 \mathrm{mg} / \mathrm{ml}$ bovine serum albumin). The reaction was terminated by addition of $90 \%$ formamide loading buffer, and the samples were separated by denaturing polyacrylamide gel $(20 \%)$ electrophoresis. The gel was dried and exposed on X-ray film. The relative fractions of full length and cut substrate were determined by densitometric analysis using Kodak Analysis Software (Kodak, Rochester, NY, USA). ${ }^{5}$

\section{Transfection of AECII cells in vitro}

A typical experiment with AECII cells for transfection used approximately $60 \times 10^{6}$ type II epithelial cells that were isolated using 6-8 rats. AECII 
$\left(5 \times 10^{6}\right)$ were plated into $60 \mathrm{~mm}$ dishes and transfected with a liposome complex (GenePorter, Gene Therapy System, San Diego, CA, USA) containing the pcDNA-hOgg1. ${ }^{31}$ From the next day, transfectants were selected by addition of neomycin $(1 \mathrm{mg} / \mathrm{ml})$ as the vectors contain a neo resistant gene. Controls in all the experiments used similar transfection methods with the vector pcDNA3.0. Initial transfection efficiency was about $20-40 \%$, selection process killed $90 \%$ untransfected cells. Signaling transduction or gene expression experiments were performed within 2 days of gene transfection. No apparent toxicity was observed with the use of neomycin. Similar methods were used to transfect dominant-negative constructs, p38 $\alpha \mathrm{AF}$ and p38 $\beta \mathrm{AF}$ (kindly provided by Dr. J Li, University of Southern California).

\section{Retroviral vector constructs and cell transduction}

The bicistronic retroviral vector pSF91.2 was constructed as described previously, ${ }^{5,32}$ with an internal ribosome entry site (IRES) upstream from the gene expressing EGFP. The plasmids were used to generate high titer ecotropic produce cell lines in GP $+\mathrm{E}-86$ cells. ${ }^{42}$ Then a transient virus was generated by transfection of the retroviral plasmid into the amphotropic producer cells, Amma + GP Env 12 cells. This virus was used to infect E86 cells. E86 cells were selected by FACS sorter via EGFP marker to obtain stable clones producing high titers of virus. The viral supernatant was used to generate hOgg1 expressing A549 cells. Initial transduction efficiency of A549 cells was about 40\%, and EGFP positive cells were sorted by FACS sorter to gain populations of approximately $>99 \%$ cells. A series of single colonies with high expression levels was selected and identified by FACS for the measurement of EGFP expression again and followed by hOgg1 activity assay for the measurement of hOgg1 expression.

\section{Growth curve and cell viability assays}

Cells were trypsinized, counted with a hemacytometer, and plated in triplicate in $60 \mathrm{~mm}$ culture dishes before being exposed to room air or hyperoxia for $24,48,72$ or $96 \mathrm{~h}$. Viability was determined by trypan blue dye exclusion. Colony-survival assays were initiated by exposing cells to room air or hyperoxia for 24 or $36 \mathrm{~h}$. Serial dilutions were replated at 300 cells per $100 \mathrm{~mm}$ culture dish and allowed to grow in room air at $37^{\circ} \mathrm{C}$ for 10-14 days, at which time colonies were fixed in 15\% methanol and stained with $2 \%$ methylene blue. The total number of colonies produced on each plate was then recorded. In addition, cytotoxicity of 24,48 and $72 \mathrm{~h}$ exposure to oxygen or parallel controls in room air was determined using a trypan blue exclusion assay (Sigma) and the MTT assay following the manufacture's instructions (Promega, Minneapolis, MN, USA). ${ }^{43}$ The MTT assay measures the cellular conversion of a Tetrazolium salt into a blue formazan product that can be easily performed in a 96 -well microtiter plate. Cells were harvested and equal number of cells ( 5000 cells/well) loaded in all wells. After hyperoxia, $15 \mu \mathrm{l}$ of working solution was added to each well and incubated at $37^{\circ} \mathrm{C}$ for $4 \mathrm{~h}$ in a humidified $5 \% \mathrm{CO}_{2}$ atmosphere or left overnight before being read at absorbance $57 \mathrm{~nm}$. Cell death was also confirmed by propidium iodide staining.

\section{Apoptosis assay}

Quantitative analysis of apoptosis in A549 cells or AECII was conducted using a histone-based Death ELISA kit (Roche) as per the manufacturer's protocol. The cells overexpressing hOgg1 or vector control were lysed. The nucleosomes containing fragmented DNA from samples were captured by immobilized antihistone antibody. The amounts of DNA fragments were then determined using peroxidase-conjugated-antiDNA antibodies and spectrophotometrically. Vybrant Apoptosis Assay Kit (Molecular Probes, Eugene, OR, USA) was also used to evaluate apoptosis as per the manufacturer's instruction. This kit can distinguish apoptotic and necrotic cells by propidium iodide dye and lipid dye (YO-PRO-1) staining. The cells were visualized using a fluorescence microscope. The dead and necrotic cells exhibit red fluorescence whereas apoptotic cells fluoresce green. The total (200 cells) and apoptotic cells were counted and the percentage of cells exhibiting apoptosis was calculated. We also analyzed apoptosis using Annexin-V-Fluos (Roche) and CMXRos (MitoTracker, Molecular Probes) Staining $(5 \mathrm{nM})$ to track the relevance of the apoptosis to mitochondria damage.

\section{RNA extraction and analysis}

RNA was extracted from cells by RNA easy kits (Qiagen, Valencia, CA, USA). The amount of RNA in an aqueous solution was determined by absorbance at $260 \mathrm{~nm}$. Semiquantitative RT-PCR was performed to determine the mRNA levels of hOgg1, p53 and p21 following hyperoxic exposure. For RT-PCR identification of hOgg1, primer sequences are: $5^{\prime}$-TTCTGGACAATCTTTCCGGTGGA-3' and 5'-GCCACCTTGGTGCC CACTCCAGGC-3' to yield a $632 \mathrm{bp}$ hOgg1 transcription product. The primers of the experiments are: p21, $5^{\prime}$-CGG-TCC-CGT-GGA-CAG-TGAGCA-G-3', 5'-GTC-AGG-CTG-GTC-TGC-CTC-CG-3'. Primers sequences for p53 are: 5'-AAT-GGA-TGA-TTT-GAT-GCT-GTC-CC-3', 5'CGT-G CA-AGT-CAC-AGA-CTT-GGC-3'. RT-PCR was performed using the Titan one-step RT-PCR kit (Roche Molecular Biochemicals) with samples of $0.2 \mu \mathrm{g}$ of total RNA as templates. The thermocycling parameters were composed of an initial cycle at $50^{\circ} \mathrm{C}$ for $30 \mathrm{~min}$ for synthesizing the first strand DNA, and then $95^{\circ} \mathrm{C}$ for $180 \mathrm{~s}$ followed by 30 cycles at $95^{\circ} \mathrm{C}$ for $60 \mathrm{~s}, 55^{\circ} \mathrm{C}$ for $60 \mathrm{~s}$ and $72^{\circ} \mathrm{C}$ for $60 \mathrm{~s}$. Several lengths of cycles $^{26,30,34}$ have been tested, and 30 cycles were used for data presentations. The mRNA level of GAPDH was used as internal control.

\section{Statistical analysis}

Experiments were performed at least three times, and representatives of the results were shown in each of the data sets. Values were expressed as means \pm S.D. Group means were compared by Student's $T$-test analysis, using SigmaPlot or Excel software, and difference was accepted at $P<0.05$.

\section{Acknowledgements}

This work is supported by the American Lung Association of Indiana, North Dakota Biomedical Research Infrastructure Network (NIH P20-164-71) and North Dakota Experimental Program to Stimulate Competitive Research (NSF) to MW. We are grateful to Drs. William J Martin and David A Williams for providing the vectors and other materials.

\section{References}

1. Conger $A$ and Fairchild $L$ (1952) Breakage of chromosomes by oxygen. Proc. Natl. Acad. Sci. USA 38: 289-299

2. Michiels C, Raes M, Toussaint $O$ and Remacle J (1994) Importance of Seglutathione peroxidase, catalase, and $\mathrm{Cu} / \mathrm{Zn}-\mathrm{SOD}$ for cell survival against oxidative stress. Free Radicals Biol. Med. 17: 235-248 
3. Sullivan SJ, Oberley TD, Roberts RJ and Spitz DR (1992) A stable O2-resistant cell line: role of lipid peroxidation byproducts in $\mathrm{O}_{2}$-mediated injury. Am. J. Physiol. 262: L748-L756

4. Cooke MS, Evans MD, Dizdaroglu M and Lunec J (2003) Oxidative DNA damage: mechanisms, mutation, and disease. FASEB J. 17: 1195-1214

5. Wu M, He Y, Xu Y, Kobune M, Kelley MR and Martin II WJ (2002) Protection of human lung cells against hyperoxia using the DNA base excision repair genes hOgg1 and Fpg. Am. J. Respir. Crit. Care Med. 166: 192-199

6. Kapanci Y, Weibel ER, Kaplan HP and Robinson FR (1969) Pathogenesis and reversibility of the pulmonary lesions of oxygen toxicity in monkeys. II. Ultrastructural and morphometric studies. Lab. Invest. 20: 101-118

7. Adamson IY, Bowden DH and Wyatt JP (1970) Oxygen poisoning in mice. Ultrastructural and surfactant studies during exposure and recovery. Arch. Pathol. 90: 463-472

8. Crapo JD, Barry BE, Foscue HA and Shelburne J (1980) Structural and biochemical changes in rat lungs occurring during exposures to lethal and adaptive doses of oxygen. Am. Rev. Respir. Dis. 122: 123-143

9. Roper JM, Mazzatti DJ, Watkins RH, Maniscalco WM, Keng PC and O'Reilly MA (2004) In vivo exposure to hyperoxia induces DNA damage in a population of alveolar type II epithelial cells. Am. J. Physiol. Lung Cell Mol. Physiol. 286: L1045-L1054

10. Wu M (2005) DNA repair proteins as molecular therapeutics for oxidative and alkylating lung injury. Curr. Gene Ther. 5: 225-236

11. Reardon JT, Bessho T, Kung HC, Bolton PH and Sancar A (1997) In vitro repair of oxidative DNA damage by human nucleotide excision repair system: possible explanation for neurodegeneration in Xeroderma pigmentosum patients. Proc. Natl. Acad. Sci. USA 294: 9463-9468

12. Izumi T, Wiederhold LR, Roy G, Roy R, Jaiswal A, Bhakat KK and Mitra S (2003) Mammalian DNA base excision repair proteins: their interactions and role in repair of oxidative DNA damage. Toxicology 193: 43-65

13. He Y, Xu Y, Wu M, Kobune M, Kelley MR and Martin II WJ (2002) E. coli FPG and human Ogg1 reduce DNA damage and cytotoxicity by BCNU in human lung cells. Am. J. Physiol. Lung Cell Mol. Physiol. 182: L50-L55

14. Hazra TK, Hill JW, Izumi T and Mitra S (2001) Multiple DNA Glycosylases for repair of 8-oxoguanine and their potential in vivo functions. Prog. Nucleic Acid. Res. Mol. Biol. 68: 193-205

15. Barazzone C and White CW (2000) Mechanisms of cell injury and death in hyperoxia: role of cytokines and Bcl-2 family proteins. Am. J. Respir. Cell Mol. Biol. 22: 517-519

16. O'Reilly MA, Staversky RJ, Watkins RH and Finkelstein JN (1998) Exposure to oxygen induces p53 expression in mouse lung epithelium. Am. J. Respir. Cell Mol. Biol. 18: 43-50

17. Rancourt RC, Staversky RJ, Keng PC and O'Reilly MA (1999) Hyperoxia inhibits proliferation of Mv1Lu epithelial cells independent of TGF- $\beta$ signaling. Am. J. Physiol. Lung Cell Mol. Physiol. 277: L1172-L1178

18. Shenberger JS and Dixon PS (1999) Oxygen induces S-phase growth arrest and increases p53 and p21(WAF1/CIP1) expression in human bronchial smooth-muscle cells. Am. J. Respir. Cell Mol. Biol. 21: 395-402

19. O'Reilly MA, Staversky RJ, Watkins RH, Reed CK, de Mesy Jensen KL, Finkelstein JN and Keng PC (2001) The cycline-dependent kinase inhibitor p21 protects the lung from oxidative stress. Am. J. Respir. Cell Mol. Biol. 24: 703710

20. Hodges NJ and Chipman JK (2002) Down-regulation of the DNA-repair endonuclease 8-oxo-guanine DNA glycosylase 1 (hOGG1) by sodium dichromate in cultured human A549 lung carcinoma cells. Carcinogenesis 23: $55-60$

21. Kinoshita A, Wanibuchi H, Imaoka S, Ogawa M, Masuda C, Morimura K, Funae $Y$ and Fukushima S (2002) Formation of 8-hydroxydeoxyguanosine and cellcycle arrest in the rat liver via generation of oxidative stress by phenobarbital: association with expression profiles of p21(WAF1/Cip1), cyclin D1 and Ogg1. Carcinogenesis 23: $341-349$

22. Davis RJ (1993) The mitogen-activated protein kinase signal transduction pathway. J. Biol. Chem. 268: 14553-14556

23. Han J and Ulevitch RJ (1999) Emerging targets for anti-inflammatory therapy. Nat. Cell Biol. 1: E39-E40

24. Zhang X, Shan P, Sasidhar M, Chupp GL, Flavell RA, Choi AM and Lee PJ (2003) Reactive oxygen species and extracellular signal-regulated kinase 1/2 mitogen-activated protein kinase mediate hyperoxia-induced cell death in lung epithelium. Am. J. Respir. Cell Mol. Biol. 28: 305-315
25. Lee PJ and Choi AM (2003) Pathways of cell signaling in hyperoxia. Free Radicals Biol. Med. 35: 341-350

26. Buckley S, Driscoll B, Barsky L, Weinberg K, Anderson K and Warburton D (1999) ERK activation protects against DNA damage and apoptosis in hyperoxic rat AEC2. Am. J. Physiol. Lung Cell Mol. Physiol. 277: L159-L166

27. Buckley S, Barsky L, Driscoll B, Weinberg K, Anderson KD and Warburton D (1998) Apoptosis and DNA damage in type 2 alveolar epithelial cells cultured from hyperoxic rats. Am. J. Physiol. 274: L714-L720

28. Hirose Y, Katayama M, Stokoe D, Haas-Kogan DA, Berger MS and Pieper RO (2003) The p38 mitogen-activated protein kinase pathway links the DNA mismatch repair system to the G2 checkpoint and to resistance to chemotherapeutic DNA-methylating agents. Mol. Cell Biol. 23: 8306-8315

29. Jaiswal AS, Bloom LB and Narayan S (2002) Long-patch base excision repair of apurinic/apyrimidinic site DNA is decreased in mouse embryonic fibroblast cell lines treated with plumbagin: involvement of cyclin-dependent kinase inhibitor p21Waf-1/Cip-1. Oncogene 21: 5912-5922

30. Spragg RG and Li J (2000) Effects of phosphocholine cytidylytransferase expression on phosphatidylcholine synthesis in alveolar type II cells and related cell lines. Am. J. Respir. Cell Mol. Biol. 22: 116-124

31. Wu M, Kelley MR, Hansen WK and Martin II WJ (2001) Reduction of BCNU toxicity to lung cells by high-level expression of $0^{6}$-methylguanine-DNA methyltransferease. Am. J. Physiol. Lung Cell Mol. Physiol. 280: L755-L761

32. Wu M, Hussain S, He HY, Pasula R, Smith PA and Martin II WJ (2001) Genetically engineered macrophages expressing IFN- $\gamma$ restore alveolar immune function in scid mice. Proc. Natl. Acad. Sci. USA 98: 14589-14594

33. Waldman T, Kinzler KW and Vogelstein B (1995) p21 is necessary for the p53-mediated G1 arrest in human cancer cells. Cancer Res. 55: 5187-5190

34. Dobbs LG (1990) Isolation and culture of alveolar type II cells. Am. J. Physiol. Lung Cell Mol. Physiol. 258: L134-L147

35. Miller BE, Chapin RE, Pinkerton MRRKE, Gilmore LB and Hook GE (1987) Quantitation of silica-induced type II cells hyperplasia by using alkaline phosphatase histochemistry in glycol methacrylate embedded lung. Exp. Lung Res. 12: 135-148

36. Bates SR, Gonzales LW, Tao JQ, Rueckert P, Ballard PL and Fisher AB (2002) Recovery of rat type II cell surfactant components during primary cell culture. Am. J. Physiol. Lung Cell Mol. Physiol. 282: L267-L276

37. Martin II WJ, Gadek JE, Hunninghake GW and Crystal RG (1981) Oxidant injury of lung parenchymal cells. J. Clin. Invest. 68: 1277-1288

38. Martin II WJ and Kachel DL (1989) Oxygen-mediated impairment of human pulmonary endothelial cell growth: evidence for a specific threshold of toxicity. J. Lab. Clin. Med. 113: 413-421

39. Wu M, Stockley PG and Martin II WJ (2002) An improved Western blotting effectively reduces the background. Electrophoresis 23: 2373-2376

40. Tokunaga I, Kubo S, Mikasa H, Suzuki Y and Morita K (1997) Determination of 8-hydroxy-deoxyguanosine formation in rat organs: assessment of paraquatevoked oxidative DNA damage. Biochem. Mol. Biol. Int. 43: 73-77

41. Toyokuni S, Tanaka T, Hattori Y, Nishiyama Y, Yoshida A, Uchida K, Hiai H, Ochi $\mathrm{H}$ and Osawa T (1997) Quantitative immunohistochemical determination of 8-hydroxy-2'-deoxyguanosine by a monoclonal antibody N45.1: its application to ferric nitrilotriacetate-induced renal carcinogenesis model. Lab. Invest. 76: 365-374

42. Markowitz DG, Goff SP and Bank A (1988) Construction and use of a safe and efficient amphotropic packaging cell line. Virology 167: 400-406

43. Wu M, Brown WL and Stockley PG (1995) Cell-specific delivery of bacteriophage-encapsidated ricin A chain. Bioconjugate Chem. 6: 587-595

44. Parinandi N, Kelinberg M, Usatyuk P, Cummings R, Pennathur A, Cardounel A, Zweier J, Garcia J and Natarajan V (2003) Hyperoxia-induced NAD(P)H oxidase activation and regulation by MAP kinases in human lung endothelial cells. Am. J. Physiol. Lung Cell Mol. Physiol. 284: L26-L38

45. Guthmann F, Wissel $H$, Schachtrup C, Tolle A, Rudiger M, Spener F and Rustow B (2005) Inhibition of TNFalpha in vivo prevents hyperoxia-mediated activation of caspase 3 in type II cells. Respir. Res. 6: 10

46. Davis RJ (2000) Signal transduction by the JNK group of MAP kinases. Cell 103: $239-252$

47. Nishimura $S$ (2001) Mammalian Ogg1/Mmh gene plays a major role in repair of the 8-hydroxyguanine lesion in DNA. Prog. Nucleic Acid. Res. Mol. Biol. 68: $107-123$ 
48. Jaiswal M, LaRusso NF, Nishioka N, Nakabeppu $Y$ and Gores GJ (2001) Human Ogg1, a protein involved in the repair of 8-oxoguanine, is inhibited by nitric oxide. Cancer Res. 61: 6388-6393

49. Wikman H, Risch A, Klimek F, Schmezer P, Spiegelhalder B, Dienemann $H$, Kayser K, Schulz V, Drings P and Bartsch H (2000) hOGG1 polymorphism and loss of heterozygosity (LOH): significance for lung cancer susceptibility in a Caucasian population. Int. J. Cancer 88: 932-937

50. Hanaoka T, Sugimura H, Nagura K, Ihara M, Li XJ, Hamada GS, Nishimoto I, Kowalski LP, Yokota J and Tsugane S (2001) hOGG1 exon7 polymorphism and gastric cancer in case-control studies of Japanese Brazilians and nonJapanese Brazilians. Cancer Lett. 170: 53-61

51. Xu J, Zheng SL, Turner A, Isaacs SD, Wiley KE, Hawkins GA, Chang BL, Bleecker ER, Walsh PC, Meyers DA and Isaacs WB (2002) Associations between hOGG1 sequence variants and prostate cancer susceptibility. Cancer Res. 62: 2253-2257

52. Xu Y, Hansen WK, Rosenquist TA, Williams DA, Limp-Foster M and Kelley MR (2001) Protection of mammalian cells against chemotherapeutic agents thiotepa, 1,3-N,N -Bis(2-chloroethyl)- $N$-nitrosourea, and mafosfamide using the DNA Base excision repair genes Fpg and $\alpha$-hOgg1: implications for protective gene therapy applications. J. Pharmacol. Exp. Ther. 296: 825-831
53. Sobol RW, Kartalou M, Almeida KH, Joyce DF, Engelward BP, Horton JK, Prasad R, Samson LD and Wilson SH (2003) Base excision repair intermediates induce p53-independent cytotoxic and genotoxic responses. J. Biol. Chem. 278: 39951-39959

54. Kapoor M and Lozano G (1998) Functional activation of p53 via phosphorylation following DNA damage by UV but not gamma radiation. Proc. Natl. Acad. Sci. USA 95: 2834-2837

55. Fisher RP and Morgan DO (1994) A novel cyclin associates with MO15/CDK7 to form the CDK-activating kinase. Cell 78: 713-724

56. Pagano A and Barazzone-Argiroffo $C$ (2003) Alveolar cell death in hyperoxiainduced lung injury. Ann. NY Acad. Sci. 1010: 405-416

57. Mantell LL, Horowitz S, Davis JM and Kazzaz JA (1999) Hyperoxia-induced cell death in the lung-the correlation of apoptosis, necrosis, and inflammation. Ann. NY Acad. Sci. 887: 171-180

58. Wu M and Wei Y (2004) Development of respiratory stem cells and progenitor cells. Stem Cells Dev. 13: 607-613

59. Skillrud DM and Martin II WJ (1984) The isolation of rat alveolar type II cells: a simplified approach using Percoll density centrifugation. Lung 162: 245-252 